\title{
Carrageenan-induced granuloma and iron status in rats with dietary polyunsaturated fatty acid deficiency
}

\author{
BY T. CARBONELL, M. P. SAIZ AND M. T. MITJAVILA* \\ Departamento de Bioquimica y Fisiologia, Facultad de Biologia, Universidad de Barcelona, \\ Avenida Diagonal 645, E-08071-Barcelona, Spain \\ AND P. PUIG-PARELLADA \\ Departamento de Farmacologia, Facultad de Medicina, Universidad de Barcelona, \\ E-08028-Barcelona, Spain \\ AND C. CAMBON-GROS, Y. FERNANDEZ AND S. MITJAVILA \\ Université Paul Sabatier, Institut de Physiologie, INSERM U-87, 31400-Toulouse, France
}

(Received 7 February 1990 - Accepted 6 September 1990)

\begin{abstract}
Sprague-Dawley rats were fed for 4 months on a control diet or a polyunsaturated-fatty-acid (PUFA)deficient diet. The combined effects of iron overload (Fe dextran) or Fe deficiency (desferrioxamine) on carrageenan-induced granuloma were studied. PUFA deficiency induced changes in Fe metabolism, but no alterations in lipid peroxidation variables were observed. Inflammation implied an increase in lipid peroxidation, Fe storage and caeruloplasmin concentration, together with symptoms of anaemia. PUFA deficiency in inflamed rats gave rise to a lower inflammatory response (granuloma weight and prostaglandin $E_{2}$ concentration) and ethane exhalation. Fe overload potentiated inflammatory and lipid peroxidation processes, whereas $\mathrm{Fe}$ deficiency decreased them.
\end{abstract}

Fatty acids: Iron status: Carrageenan-induced granuloma: Rat

Inflammatory processes are related to lipid peroxidation of the membranes mediated by low molecular weight iron (Gutteridge et al. 1981) and implicate an increase in prostaglandin $\mathrm{E}_{2}$ synthesis (Yoshino et al. 1984). It has been suggested that $\mathrm{Fe}$ dextran induces an exacerbation of the inflammatory diseases (Winyard et al. 1987) while high levels of desferrioxamine (Fe-chelating drug) reduce inflammation but the effects are dependent on the administered dose (Blake et al. 1983).

The type of fatty acid in the diet strongly influences the fatty-acid composition of tissue and serum lipids (Morganroth et al. 1987), and eicosanoid metabolism is largely dependent on the amount and type of fatty-acid precursor in the diet (Codde et al. 1985; Terano et al. 1986). Thus, eicosapentaenoic acid (EPA; 20:5n-3), precursor of the $n-3$ eicosanoid family, has been relevant in the treatment of arthritis either in experimental models (McColl et al. 1987) or in clinical situations (Kremer et al. 1985, 1987; Moncada \& Salmon 1986). Moreover, polyunsaturated-fatty-acid (PUFA)-deficient diet is associated with changes in physical properties of the membrane, which lead to altered bound-enzyme, transport proteins (Cambon-Gros et al. 1989) as well as lowering the production of free radicals, hydroperoxides and aldehydes (Christon et al. 1988). PUFA-deficient diet also induces the substitution of the physiological eicosanoid precursor by a non-suitable substrate for the cyclooxygenase enzyme system (EC 1.14.99.1; Ziboth et al. 1974).

\footnotetext{
* For reprints.
} 
Direct proof for the combined role of Fe and PUFA in inflammation (carrageenaninduced granuloma in rats) has not been demonstrated. Accordingly we have studied the effect of $\mathrm{Fe}$ status ( $\mathrm{Fe}$ overload or Fe deficiency) in inflamed rats submitted to a control or a PUFA-deficient diet. Indicators of inflammation, PUFA oxidation and Fe variables were determined.

\section{MATERIALS AND METHODS \\ Animals and diets}

The experiments were carried out on forty male Sprague-Dawley rats. After weaning they were separated in two equal groups. One group was fed with commercially available rat chow $\left(\mathrm{UAR}^{\mathrm{R}}\right.$; Villemoison, France), containing $50 \mathrm{~g}$ fat $/ \mathrm{kg}$ ( $25 \mathrm{~g}$ rapeseed oil and $25 \mathrm{~g}$ peanut oil $/ \mathrm{kg}$; control diet). The other group was offered a diet $\left(\mathrm{UAR}^{\mathrm{R}}\right)$ containing $50 \mathrm{~g}$ tripalmitin/kg (PUFA-deficient diet). On analysis by flame atomic absorption spectrophotometry both diets contained $58 \mathrm{mg} \mathrm{Fe} / \mathrm{kg}$.

\section{Pretreatment of experimental animals}

After 4 months of treatment each group was divided into four subgroups of five rats. All $\mathrm{C}$ and $\mathrm{D}$ groups received control and deficient diets respectively (see Table 1). The pretreatments for inflamed rats (I) were: on day 0, a carrageenan granuloma pouch (Fukuhara \& Tsurufuji, 1969) was induced by a dorsal injection of $5 \mathrm{ml}$ air, followed $24 \mathrm{~h}$ later by $4 \mathrm{ml}$ carrageenan $(20 \mathrm{~g} / \mathrm{l}$ ) (Viscarin 402, Marine Colloids, Springfield, NJ) (groups $\mathrm{CI}$ and DI). Fe overload (Imf) was induced by injection of Fe dextran (Imferon, Instituto Llorente, Barcelona, Spain) at $50 \mathrm{mg} \mathrm{Fe} / \mathrm{kg}$ body-weight into the granuloma pouch on days 0,3 and 5 (groups CIImf and DIImf). Fe deficiency (Dfx) was induced by a daily subcutaneous injection of desferrioxamine (Desferin, Ciba-Geigy, Barcelona, Spain) at $100 \mathrm{mg} / \mathrm{kg}$ body-weight, $2 \mathrm{~d}$ before the granuloma induction, and into the granuloma pouch on the following $5 \mathrm{~d}$ (groups CIDfx and DIDfx). Rats were killed $6 \mathrm{~d}$ after the granuloma induction. Desferrioxamine was dissolved in sterile saline $(9 \mathrm{~g}$ sodium chloride/1) treated with Chelex-100 (Bio-Rad Laboratories, Richmond, CA). All groups received the corresponding volume of saline treated with Chelex-100 in order to obtain the same final liquid volume injected.

\section{Analytical techniques}

At the end of the pretreatment period, four rats of each group were placed together for $4 \mathrm{~h}$ in a specially-designed expired gases collection chamber which enabled the monitoring in vivo of the peroxidative degradation of polyunsaturated lipids. Ethane production is a good indicator of $n-3$ fatty acid peroxidation. Changes in the level of ethane production between groups may be due to a lower peroxidation of $n-3$ fatty acids or to a relatively higher content of other fatty acids, such as $n-9$ which gives octane, undetectable in expired gases. The ethane content of the gas phase was measured in samples of $10 \mathrm{ml}$ injected into a gas-chromatograph equipped with a flame ionization detector. The column used was $2 \mathrm{~m} \times 2 \mathrm{~mm}$ packed with Poropak Q (Waters Associates, Framingham, MA) 100-200 mesh. Gas flow was helium at $35 \mathrm{ml} / \mathrm{min}$. The column temperature was programmed from $50^{\circ}$ to $170^{\circ}$. Samples were taken within $5 \mathrm{~min}$ after the animals were sealed in the chambers (this value was subtracted from all subsequent ethane determinations) and at 1,2,3, and $4 \mathrm{~h}$.

Then the animals were anaesthetized with diethyl ether and exsanguinated by cardiac puncture. The granuloma and the liver were removed and weighed. The non-haem-Fe (Torrance \& Bothwell, 1968) and the ferritin-Fe (Drysdale \& Munro, 1965) levels in the liver were measured. Packed cell volume, haemoglobin concentration (Drabkin \& Austin, 
Table 1. Body-weight, liver-weight and liver iron content of rats offered different diets and pretreatments*

(Results are means with their standard errors for five rats)

\begin{tabular}{|c|c|c|c|c|c|c|c|c|}
\hline \multirow[b]{2}{*}{ Group } & \multicolumn{2}{|c|}{$\begin{array}{l}\text { Body-wt } \\
\text { (g) }\end{array}$} & \multicolumn{2}{|c|}{$\begin{array}{l}\text { Liver-wt } \\
\text { (g) }\end{array}$} & \multicolumn{2}{|c|}{$\begin{array}{l}\text { Ferritin-Fe } \\
\quad(\mu \mathrm{g} / \mathrm{g})\end{array}$} & \multicolumn{2}{|c|}{$\begin{array}{c}\text { Non-haem-Fe } \\
(\mu \mathrm{g} / \mathrm{g})\end{array}$} \\
\hline & Mean & $\mathrm{SE}$ & Mean & $\mathrm{SE}$ & Mean & SE & Mean & $\mathrm{SE}$ \\
\hline $\mathrm{C}$ & $422^{\mathrm{ab}}$ & 13 & $103^{a b}$ & $0 \cdot 40$ & $18^{\mathrm{c}}$ & $1 \cdot 6$ & $128^{\mathrm{e}}$ & 8 \\
\hline D & $391^{\text {be }}$ & 11 & $10 \cdot 7^{\mathrm{a}}$ & 0.52 & $60^{\mathrm{ab}}$ & $9 \cdot 6$ & $186^{\mathrm{cd}}$ & 22 \\
\hline CI & $378^{\mathrm{bc}}$ & 22 & $9 \cdot 8^{a b}$ & 0.57 & $23^{\mathrm{e}}$ & $2 \cdot 1$ & $159^{d}$ & 9 \\
\hline DI & $396^{\mathrm{ab}}$ & 14 & $9 \cdot 1^{\text {be }}$ & $0 \cdot 35$ & $48^{b}$ & $4 \cdot 2$ & $253^{\mathrm{bc}}$ & 22 \\
\hline CIImf & $458^{\mathrm{a}}$ & 23 & $9 \cdot 7^{a b c}$ & 0.59 & $37^{\mathrm{b}}$ & $3 \cdot 1$ & $303^{b}$ & 26 \\
\hline DIImf & $395^{\mathrm{abc}}$ & 17 & $9 \cdot 5^{\mathrm{abc}}$ & 0.38 & $70^{\mathrm{a}}$ & 5.0 & $519^{a}$ & 37 \\
\hline CIDf $x$ & $437^{\mathrm{a}}$ & 12 & $9 \cdot 8^{\mathrm{ab}}$ & 0.55 & $22^{\mathrm{c}}$ & $2 \cdot 5$ & $106^{\mathrm{e}}$ & 9 \\
\hline DIDfx & $358^{\mathrm{c}}$ & 18 & $8 \cdot 1^{\circ}$ & $0 \cdot 42$ & $21^{\mathrm{e}}$ & $3 \cdot 3$ & $138^{\text {de }}$ & 22 \\
\hline
\end{tabular}

$a, b, c, d, e$ Values in the same column with different superscript letters were significantly different (Miller's multiple comparison test): $P<0 \cdot 05$.

C, control diet; D, polyunsaturated fatty acid (PUFA)-deficient diet; CI, control diet and inflamed; DI, PUFAdeficient diet and inflamed; CIImf, control diet, inflamed and pretreated with imferon; DIImf, PUFA-deficient diet, inflamed and pretreated with imferon; CIDfx, control diet, inflamed and pretreated with desferrioxamine; DIDfx, PUFA-deficient diet, inflamed and pretreated with desferrioxamine.

* For details of diets and pretreatments, see p. 498.

1935), plasma Fe concentration and total Fe binding capacity (International Committee for Standardization in Haematology, 1971) were assayed immediately. The following variables were examined in plasma samples frozen in liquid nitrogen and stored at $-80^{\circ}$ for a few days: caeruloplasmin was measured as its $p$-phenylenediamine oxidase $(E C$ 1.4.3.6) activity (Sunderman \& Nomoto, 1970), malondialdehyde by the thiobarbituric acid reaction (Yagi, 1976) and prostaglandin $\mathrm{E}_{2}$ by radioimmunoassay (Saragen Inc., Boston, Mass).

\section{Statistical methods}

Results are expressed as means for five rats with corresponding standard errors. Data were evaluated by the one-way analysis of variance with eight groups per variable. When the variable effect was statistically significant, the groups were compared pairwise by a multiple comparison method (Miller, 1966). The means are given several superscript letters thus allowing the comparison of the statistical significance between groups $(P<0.05)$. Groups from the same column having at least one common superscript letter are not statistically different.

\section{RESULTS}

The main object of this study was the effect of Fe status on inflammatory variables in normal and PUFA-deficient rats. The results (Table 1) show that no important alterations in body and liver weights were observed, except in group DIDfx. PUFA deficiency induced an increase in Fe storage in the liver. Inflammation had a significant increasing effect only in non-haem-Fe stores in the liver of control rats, while Fe-overloading groups gave the highest content. A clear decrease in liver Fe content was observed when comparing the corresponding inflamed groups (CI and DI) with their respective desferrioxamine pretreated groups (CIDfX and DIDfx).

The more relevant results in blood variables related directly or indirectly to Fe (Table 2) 
Table 2. Packed cell volume ( $P C V)$, blood haemoglobin $(H b)$, plasma iron concentration, total Fe-binding capacity $(T I B C)$, transferrin saturation and caeruloplasmin $(C p)$ concentration in rats offered different diets and pretreatments*

(Results are means with their standard errors for five rats)

\begin{tabular}{|c|c|c|c|c|c|c|c|c|c|c|c|}
\hline \multirow[b]{2}{*}{ Group } & \multicolumn{2}{|c|}{ PCV } & \multicolumn{2}{|c|}{$\begin{array}{c}\mathrm{Hb} \\
(\mathrm{g} / 1)\end{array}$} & \multicolumn{2}{|c|}{$\begin{array}{c}\text { Plasma Fe } \\
(\mu \mathrm{g} / 1)\end{array}$} & \multicolumn{2}{|c|}{$\begin{array}{l}\text { TIBC } \\
(\mu \mathrm{g} / 1)\end{array}$} & \multirow{2}{*}{$\frac{\begin{array}{c}\text { Transferrin } \\
\text { (saturation \%) }\end{array}}{\text { Mean }}$} & \multicolumn{2}{|c|}{$\begin{array}{c}\mathrm{Cp} \\
(\mathrm{mg} / 1)\end{array}$} \\
\hline & Mean & $\mathrm{SE}$ & Mean & $\mathrm{SE}$ & Mean & $\mathrm{SE}$ & Mean & $\mathrm{SE}$ & & Mean & $\mathrm{SE}$ \\
\hline $\mathrm{C}$ & $0.46^{\mathrm{ab}}$ & 0.013 & $144^{a}$ & $4 \cdot 0$ & $1310^{c}$ & 160 & $4910^{\mathrm{b}}$ & 290 & 27 & $270^{\mathrm{d}}$ & 25 \\
\hline $\mathrm{D}$ & $0.46^{\mathrm{ab}}$ & 0.013 & $139^{\mathrm{a}}$ & $2 \cdot 7$ & $1730^{\mathrm{bc}}$ & 330 & $5020^{\mathrm{b}}$ & 320 & 34 & $320^{d}$ & 34 \\
\hline $\mathrm{CI}$ & $0.42^{\mathrm{b}}$ & 0.019 & $111^{c}$ & $7 \cdot 8$ & $1120^{\mathrm{c}}$ & 50 & $3590^{\mathrm{c}}$ & 120 & 31 & $490^{c}$ & 15 \\
\hline DI & $0 \cdot 46^{\mathrm{ab}}$ & $0 \cdot 006$ & $136^{\mathrm{ab}}$ & $3 \cdot 4$ & $1910^{\mathrm{b}}$ & 110 & $5140^{\mathrm{n}}$ & 260 & 37 & $710^{\mathrm{ab}}$ & 10 \\
\hline CIImf & $0.47^{\mathrm{ab}}$ & 0.002 & $121^{c}$ & 1.6 & $4870^{\mathrm{a}}$ & 120 & $7300^{\mathrm{a}}$ & 500 & 67 & $530^{\mathrm{bc}}$ & 34 \\
\hline DIImf & $0.48^{\mathrm{a}}$ & 0.012 & $129^{\mathrm{bc}}$ & $3 \cdot 2$ & $7660^{\mathrm{a}}$ & 1550 & $10260^{\mathrm{a}}$ & 1590 & 75 & $710^{\mathrm{a}}$ & 36 \\
\hline CIDf $x$ & $0.47^{a b}$ & 0.007 & $116^{\circ}$ & $4 \cdot 7$ & $1570^{\mathrm{bec}}$ & 310 & $4810^{b}$ & 140 & 33 & $540^{\mathrm{bx}:}$ & 43 \\
\hline DIDfx & $0.46^{\mathrm{ab}}$ & 0.002 & $126^{\mathrm{bc}}$ & $3 \cdot 9$ & $1540^{\mathrm{bc}}$ & 490 & $4610^{b}$ & 290 & 33 & $670^{\mathrm{ab}}$ & 56 \\
\hline
\end{tabular}

a. b, c, d Values in the same column with different superscript letters were significantly different (Miller's multiple comparison test): $P<0-05$.

$\mathrm{C}$, control diet; D, polyunsaturated fatty acid (PUFA)-deficient diet; Cl, control diet and inflamed; DI, PUFAdeficient diet and inflamed; CIImf, control diet, inflamed and pretreated with imferon; DIImf, PUFA-deficient diet, inflamed and pretreated with imferon; CIDfx, control diet, inflamed and pretreated with desferrioxamine; DIDfx, PUFA-deficient diet, inflamed and pretreated with desferrioxamine.

* For details of diets and pretreatments, see p. 498.

Table 3. Granuloma-weight and blood prostaglandin $E_{2}\left(P G E_{2}\right)$ and malondialdehyde $(M D A)$ concentrations in rats offered different diets and pretreatments*

(Results are means with their standard errors for five rats)

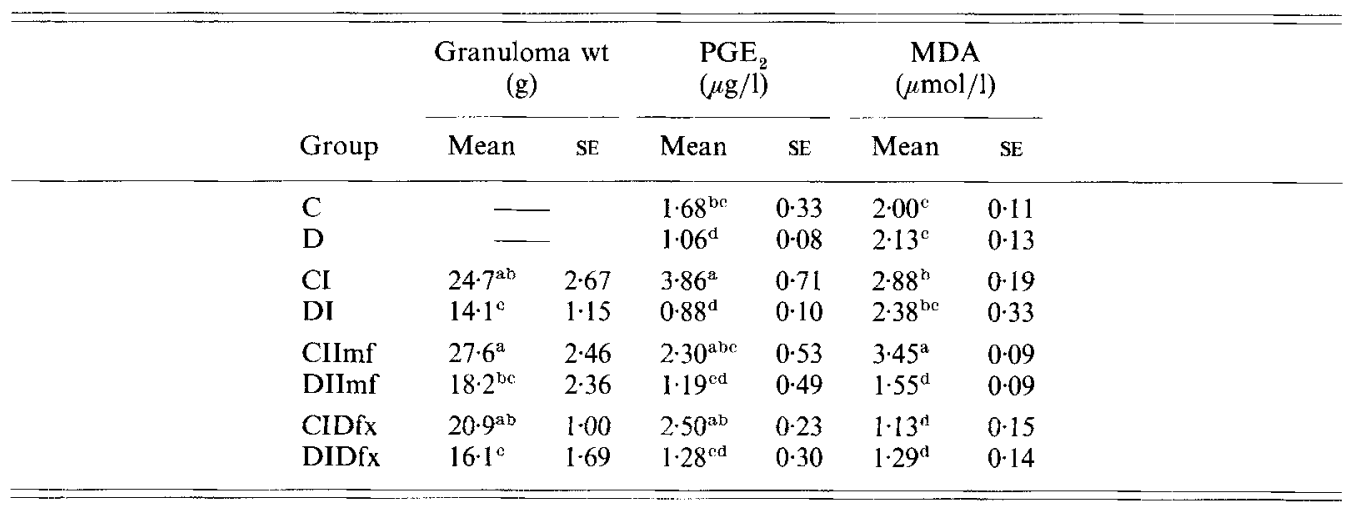

a, b, c, d Values in the same column with different superscript letters were significantly different (Miller's multiple comparison test): $P<0.05$.

C, control diet; D, polyunsaturated fatty acid (PUFA)-deficient diet; CI, control diet and inflamed; DI, PUFAdeficient diet and inflamed; CIImf, control diet, inflamed and pretreated with imferon; DIImf, PUFA-deficient diet, inflamed and pretreated with imferon; CIDfx, control diet, inflamed and pretreated with desferrioxamine; DIDfx, PUFA-deficient diet, inflamed and pretreated with desferrioxamine.

* For details of diets and pretreatments, see p. 498.

were the alterations induced by inflammation itself or by the PUFA deficiency in haemoglobin, plasma Fe, total Fe-binding capacity, transferrin saturation and caeruloplasmin with regard to their respective controls. In all groups, inflammation induced a significant increase in caeruloplasmin levels, which was more important in PUFA- 


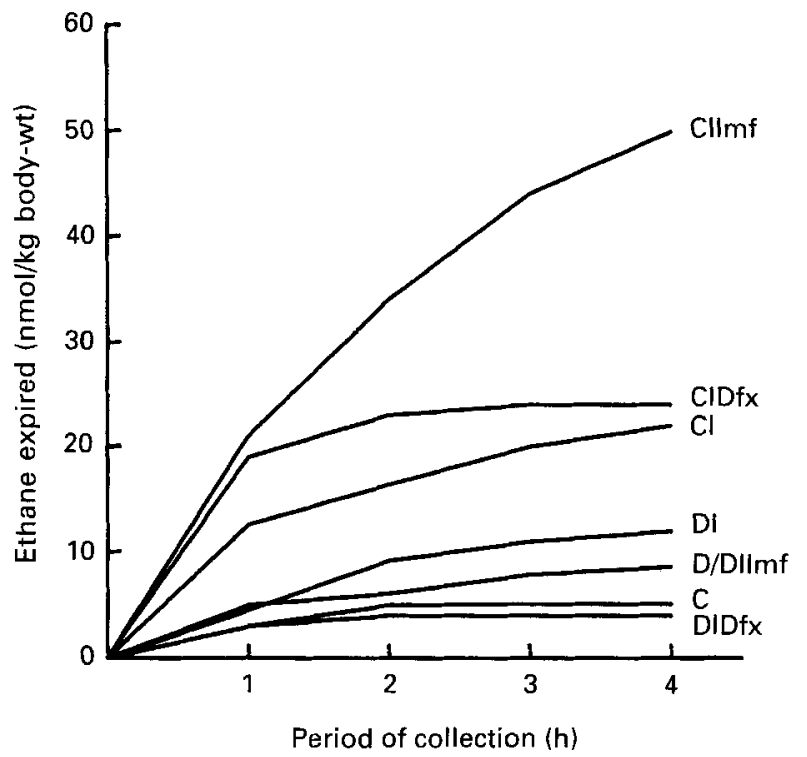

Fig. 1. Accumulated values of ethane expired by different groups of four rats placed together in a collection chamber and offered different diets and pretreatments. For details of diets and pretreatments see p. 498 . C, control diet; D, polyunsaturated fatty acid (PUFA)-deficient diet; CI, control diet and inflamed; DI, PUFA-deficient diet and inflamed; CIImf, control diet, inflamed and pretreated with imferon; DIImf, PUFA-deficient diet, inflamed and pretreated with imferon; CIDfx, control diet, inflamed and pretreated with desferrioxamine; DIDfx, PUFAdeficient diet, inflamed and pretreated with desferrioxamine.

deficient rats. This seemed to be independent of Fe because both overloading and desferrioxamine treatments were without effect.

Table 3 shows results concerning the inflammatory process. In all groups offered a deficient diet (groups D, DI, DIImf and DIDfx) in relation to their respective controls (C, CI, CIImf and CIDfx) there was a significant decrease in granuloma weight (with the exception of groups $C$ and $D$, which were not inflamed), and in plasma prostaglandin $E_{2}$ concentration. In group CI, prostaglandin $\mathrm{E}_{2}$ and malondialdehyde levels were significantly increased in comparison with group $\mathrm{C}$. The Fe pretreatment in inflamed rats (CIImf) increased the malondialdehyde levels whereas desferrioxamine (CIDfx) had an opposite effect with regard to group CI. The differences in the malondialdehyde level were only statistically significant in DIImf rats. Variations in ethane exhalation were also observed (Fig. 1): group CIImf showed the greatest values while PUFA deficiency induced a decrease in the ethane exhaled by inflamed rats pretreated with Imferon or with desferrioxamine (DIImf and DIDfx) when compared with their controls (CIImf and CIDfx).

\section{DISCUSSION}

In relation to the control group, PUFA deficiency gives rise to a less inflammatory activity which is expressed as a lower granuloma weight together with a lower prostaglandin $\mathrm{E}_{2}$ concentration in the plasma, suggesting that the inflammatory response is directly related to the lipid constituents of the diet. In this sense, it has been observed that when rats are maintained on a PUFA-deficient diet, arachidonic acid $(20: 4 n-6)$ and homo $\gamma$-linolenic acid $(20: 3 n-6)$ (prostaglandin precursors) are mainly substituted by eicosatrienoic acid $(20: 3 n-9)$ (Morganroth et al. 1987) which is not a proper substrate for the cyclooxygenase enzyme system activity (Ziboth et al. 1974).

Inflammation induces an increase in the synthesis of some acute-phase proteins such as ferritin (Konijn et al. 1981) and caeruloplasmin (Rice, 1961). Surprisingly enough, in 
inflamed PUFA-deficient rats, which consequently show a low inflammatory response, the caeruloplasmin concentration is more elevated and related to increased Fe variables in blood and liver. Osaki \& Johnson (1969) postulated that caeruloplasmin is required for the oxidation of $\mathrm{Fe}$ at the cell surface before this Fe can be bound to transferrin. In addition, caeruloplasmin acts as a superoxide radical scavenger (Goldstein et al. 1979) and according to Samokyszyn et al. (1989) it also inhibits superoxide and ferritin-dependent lipid peroxidation, largely via its ability to reincorporate reductively-mobilized-Fe back into ferritin by feroxidase activity. These facts could explain the increase in caeruloplasmin levels in control inflamed rats and in PUFA-deficient rats as a defence mechanism in the presence of increased iron stores.

As the diet is implicated in the inflammatory response, we became interested in the effect of dietary lipids on the peroxidation capacity of the cell. In this sense, we must take into account the fact that the oxidative degradation of $20: 3 n-9$ leads to the formation of other biologically-active metabolites such as 4-hydroxyundecenal and other compounds (Benedetti et al. 1980). This activity is not very well known, but may explain the maintenance of lipid peroxidation levels in rats offered the PUFA-deficient diet (group D). However, the PUFA-deficient diet in the Fe-overload group gives rise, in relation to its control group, to a decrease in the production of malondialdehyde levels together with an increase in plasma Fe. We believe that these alterations are independent: the decrease in lipid peroxidation is related, according to Lefkowith (1988), to the depressed levels of macrophages in the exudate as a result of the diet; the changes observed in Fe metabolism as a consequence of the PUFA-deficient diet cannot easily be explained and need further research. However, findings have been published on the interrelationship of dietary factors and Fe absorption (Davis \& Deller, 1966; Van Campen, 1974; Monsen \& Cook, 1979), and according to Van Dokkum et al. (1983) an increase of linoleic acid $(18: 2 n-6)$ intake causes a reduction in the $\mathrm{Fe}$ balance.

In our experimental work some efforts have been directed to the role of Fe deficiency in inflammation. Desferrioxamine pretreatment induces alterations in lipid peroxidation, possibly related to its activity as an Fe-chelating agent. The anti-inflammatory action of this drug supports the suggestion that $\mathrm{Fe}$ has an important role in the initiation and maintenance of inflammation (Blake et al. 1983), but high doses of desferrioxamine must be administered as it is excreted very rapidly, making it difficult to achieve concentrations high enough to chelate Fe effectively (Peters et al. 1966).

In summary, our findings show that a PUFA-deficient diet is able to reduce the inflammatory response and alter the peroxidation capacity of the cells. Fe plays a different role in lipid peroxidation according to the presence or absence of PUFA in the diet.

This work was supported by the Comisión Asesora Cientifica y Técnica (CAICYT) PB850234 and by the Acción Integrada Hispano-Francesa 1987 (16/130) y 1988(9/101). The authors also thank Miss J. Valentin for her technical assistance.

\section{REFERENCES}

Benedetti, A., Comporti, M. \& Esterbauer, H. (1980). Identification of 4-hydroxynonenal as a cytotoxic product originating from the peroxidation of liver microsomal lipids. Biochimica et Biophysica Acta 620, 281 --296.

Blake, D. R., Hall, N. D., Bacon, P. A., Dieppe, P. A., Halliwell, B. \& Gutteridge, J. M. C. (1983). Effect of a specific iron chelating agent on animal models of inflammation. Annals of Rheumatic Diseases 42, 89-93.

Cambon-Gros, C., Fernandez, Y., Mitjavila, M. T., Carbonell, T., Puig-Parellada, P. \& Mitjavila, S. (1990). Combined effect of a PUFA deficient diet and iron levels on lipid peroxidation induced by $\mathrm{CCl}_{4}$. Food Additives and Contaminants 7, 5108-5110.

Christon, R., Fernandez, Y., Cambon-Gros, C., Periquet, A., Deltour, P., Leger, C. \& Mitjavila, S. (1988). The effect of dietary essential fatty acid deficiency on the composition and properties of the liver microsomal membrane of rats. Journal of Nutrition 112, 1311-1318. 
Codde, J. P., Beilin, L. J., Croft, K. D. \& Vandongen, R. (1985). Study of diet and drug interactions on prostanoid metabolism. Prostaglandins 29, 895-910.

Davis, P. S. \& Deller, D. J. (1966). Prediction and demonstration of iron chelating ability of sugars. Nature 212 , $404-405$

Drabkin, D. L. \& Austin, J. H. (1935). Spectrophotometric studies II. Preparation from washed blood cells: nitric oxide hemoglobin and sulphohemoglobin. Journal of Biological Chemistry 112, 51-64.

Drysdale, J. W. \& Munro, H. N. (1965). The separation of ferritin and hemosiderin for studies in the metabolism of iron. Biochemical Journal 95, 851-858.

Fukuhara, M. \& Tsurufuji, S. (1969). The effect of locally injected anti-inflammatory drugs on the carrageenan granuloma in rats. Biochemical Pharmacology 18, 475-484.

Goldstein, I. M., Kaplan, H. B., Edelson, H. S. \& Weissmann, G. (1979). Caeruloplasmin: a scavenger of superoxide anion radicals. Journal of Biological Chemistry 252, 40404045.

Gutteridge, J. M. C., Rowley, D. A. \& Halliwell, B. (1981). Superoxide-dependent formation of hydroxyl radicals in the presence of iron salts. Biochemical Journal 199, 263-265.

International Committee for Standardization in Haematology (1971). Proposed recommendations of serum iron in human blood. British Journal of Haematology 20, 451-453.

Konijn, A. M., Carmel, N., Levy, R. \& Hershko, C. (1981). Ferritin synthesis in inflammation. II. Mechanism of increased ferritin synthesis. British Journal of Haematology 49, 361-370.

Kremer, J. M., Bigaouette, J., Michalek, A. V., Timchalk, M. A., Lininger, Ll., Rynes, R. I., Huyck, C., Zieminski, J. \& Bartholomew, L. E. (1985). Effects of manipulation of dietary fatty acids on clinical manifestations of rheumatoid arthritis. Lancet i, $184-187$.

Kremer, J. M., Jubiz, W., Michalek, A., Rynes, R. I., Bartholomew, L. E., Bigaouette, J., Timchalk, M., Beeler, D. \& Lininger, Ll. (1987). Fish-oil fatty acid supplementation in active rheumatoid arthritis. A double-blind, controlled, crossover study. Annals of Internal Medicine 106, 497-503.

Lefkowith, J. B. (1988). Essential fatty acid deficiency inhibits the in vivo generation of leukotriene $\mathbf{B}_{4}$ and suppresses levels of resident and elicited leukocytes in acute inflammation. Journal of Immunology 140, $228-233$.

McColl, M. R., Cleland, L. G., Whitehouse, M. W. \& Vernon-Roberts, B. (1987). Effect of dietary polyunsaturated fatty acid (PUFA) supplementation on adjuvant induced polyarthritis in rats. Journal of Rheumatology 14, 197-201.

Miller, R. G. Jr (1966). Simultaneous Statistical Inference. New York, McGraw-Hill.

Moncada, S. \& Salmon, J. A. (1986). Leukocytes and tissue injury: The use of eicosapentaenoic acid in the control of white cell activation. Wiener Klinische Wochenschrift 98, 104-106.

Monsen, E. R. \& Cook, J. D. (1979). Food iron absorption in human subjects. V. Effects of the major dietary constituents of a semisynthetic meal. American Journal of Clinical Nutrition 32, 804-808.

Morganroth, M. L., Pickett, W. C., Worthen, S., Mathias, M., Reeves, J. T. \& Voelkel, N. F. (1987). Decreased pulmonary vascular responsiveness in rats raised on an essential fatty acid deficient diet. Prostaglandins 33, $181-197$

Osaki, S. \& Johnson, D. A. (1969). Mobilization of liver iron by ferroxidase (ceruloplasmin). Journal of Biological Chemistry 244, 5757-5758.

Peters, G., Keberle, H., Schmid, K. \& Brunner, H. (1966). Distribution and renal excretion of desferrioxamine and ferrioxamine in the dog and in the rat. Biochemical Pharmacology 15, 93-109.

Rice, E. W. (1961). Evaluation of the role of caeruloplasmin as an acute-phase reactant. Clinica Chimica Acta 6 , $652-655$.

Samokyszyn, V. M., Miller, D. M., Reif, D. W. \& Aust, S. D. (1989). Inhibition of superoxide and ferritindependent lipid peroxidation by ceruloplasmin. Journal of Biological Chemistry 264, 21-26.

Sunderman, F. W. Jr \& Nomoto, S. (1970). Measurement of human serum ceruloplasmin by its $p$ phenylenediamine oxidase activity. Clinical Chemistry 16, 903-910.

Terano, T., Salmon, J. A., Higgs, G. A. \& Moncada, S. (1986). Eicosapentaenoic acid as a modulator of inflammation. Effect on prostaglandin and leukotriene synthesis. Biochemical Pharmacology 35, 779-785.

Torrance, J. D. \& Bothwell, T. M. (I968). A simple technique for measuring storage iron concentrations in formalinized liver samples. South African Journal of Medicine 33, 9-11.

Van Campen, D. (1974). Regulation of iron absorption. Federation Proceedings 33, 100-105.

Van Dokkum, W., Cloughley, F. A., Hulshof, K. F. A. M. \& Oosterven, L. A. M. (1983). Effect of variations in fat and linoleic acid intake on the calcium, magnesium and iron balance of young men. Annals of Nutrition and Metabolism 27, 361-369.

Winyard, P. G., Blake, D. R., Chirico, S., Gutteridge, J. M. C. \& Lunec, J. (1987). Mechanism of exacerbation of rheumatoid synovitis by total-dose iron-dextran infusion: in vivo demonstration of iron-promoted oxidant stress. Lancet i, 69-72.

Yagi, K. (1976). A simple fluorimetric assay for lipoperoxide in blood plasma. Biochemical Medicine 15, 212-216.

Yoshino, S., Blake, D. R. \& Bacon, P. A. (1984). The effect of desferrioxamine on antigen-induced inflammation in the rat air pouch. Journal of Pharmacy and Pharmacology 36, 543-545.

Ziboth, V. A., Vanderhoek, J. T. \& Lands, W. M. (1974). Inhibition of sheep vesicular gland oxygenase by unsaturated fatty acids from skin of essential fatty acids deficient rats. Prostaglandins 5, 233-240. 